\title{
Sleep Hygiene Pattern and Behaviors and Related Factors among General Population in West Of Iran
}

\author{
Habibolah Khazaie ${ }^{1}$, Azita Chehri ${ }^{1,2}$, Kheirollah Sadeghi ${ }^{3}$, Fatemeh Heydarpour ${ }^{4}$, Akram Soleimani ${ }^{5}$ \& Zahra \\ Rezaei $^{6}$ \\ ${ }^{1}$ Sleep Disorders Research Center, Kermanshah University of Medical Sciences, Kermanshah, Iran \\ ${ }^{2}$ Department of Psychology, Kermanshah Branch, Islamic Azad University, Kermanshah, Iran \\ ${ }^{3}$ Department of Clinical Psychology, Faculty of Medicine, Kermanshah University of Medical Sciences, \\ Kermanshah, Iran \\ ${ }^{4}$ Ph.D. Student of Epidemiology, Emam Ali Hospital, Kermanshah University of Medical Sciences, Kermanshah, \\ Iran \\ ${ }^{5}$ Student's Research Committee, Kermanshah University of Medical Sciences, Kermanshah, Iran \\ ${ }^{6}$ Department of Educational Sciences, Kermanshah Branch, Islamic Azad University, Kermanshah, Iran \\ Correspondence: Azita Chehri, PhD of Psychology, Department of Psychology, Kermanshah Branch, Islamic \\ Azad University, P.O. Box 6719851151, Kermanshah, Iran. Tel: 98-91-8830-9946. E-mail: \\ azitachehri@yahoo.com
}

Received: September 24, 2015 Accepted: November 28, 2015 Online Published: December 17, 2015

doi:10.5539/gjhs.v8n8p114 URL: http://dx.doi.org/10.5539/gjhs.v8n8p114

\begin{abstract}
Introduction: Sleep hygiene was found as an important predictor for sleep quality. People's sleep hygiene can have a major role in their daily function. The purpose of the study was to determine sleep hygiene patterns and sleep hygiene behaviors and factors affecting them in the general population of Kermanshah, Iran.
\end{abstract}

Material and methods: In this cross-sectional study, 1829 men and 1262 women were selected randomly from 50 clusters of different parts of the city. The inclusion criteria were age between 12 and 65 years and living in Kermanshah. The exclusion criteria were psychiatric disorder and known general medical conditions that affecting sleep. The data collection instruments were demographic questionnaire and Sleep Hygiene Questionnaire, consisted of 13 items about biological rhythm and bed room environment and behaviors that affecting sleep. Data were analyzed by using SPSS version 16 software.

Results: The highest percentage was obtained for irregular woke and went up from day to day or at weekend and holidays (74.8\%). Only 213 (6.9\%) participants were classified as having good sleep hygiene (score 12-14). The mean age of very poor, poor, moderate, and good sleepers was $34.8 \pm 14.4,33.7 \pm 17.4,36.5 \pm 13.8$, and $35 \pm$ 13.7years, respectively. There were significant differences between the age of poor and moderate sleepers and also sleep hygiene patterns with respect to sex, education level and job.

Conclusion: Poor sleep hygiene were more frequent in Iranian peoples and the major problem in sleep hygiene in our study was inappropriate sleep schedule.

Keywords: Iran, Kermanshah, sleep behaviors, sleep hygiene

\section{Introduction}

Sleep a basic need, has an important effect on health (Baldwin et al., 2001; Gottlieb et al., 2006; Gottlieb et al., 2010; Kapur et al., 2002; Masa, Rubio, \& Findley, 2000; Meier-Ewert et al., 2004; Walia et al., 2014). Good sleep quality and restful sleep is needed for a good and healthy life (Ozdemir, Boysan, Selvi, Yildirim, \& Yilmaz, 2015). Sleep hygiene refers to the lifestyle behaviors and environmental conditions that facilitate sleep and improve sleep quality (American Academy of Sleep Medicine, 2005). Sleep hygiene was originally developed for the treatment of insomnia. In the recent years, there has been increased attention concerning poor sleep hygiene and habits in the general population as well (Brown, Buboltz, \& Soper, 2002).

According to the International Classification of Sleep Disorders (ICSD2: American Academy of Sleep 
Medicine), inadequate sleep hygiene behaviors are divided into five categories: inappropriate sleep schedule (e.g., napping and instability bed and wake times), the use of sleep disrupting products (e.g., caffeine and cigarettes), mentally stimulating activities close to bedtime (e.g., planning and involvement in exciting or emotionally upsetting work), involvement in activities other than sleeping in the bed room (e.g., watching television and reading), and failure to sustain a relaxed sleeping environment (e.g., uncomfortable mattress or temperature) (American Academy of Sleep Medicine, 2005).

Many studies have shown that the sleep hygiene behaviors listed above disturb sleep and may be important causes of insomnia (Stepanski \& Wyatt, 2003; Jefferson et al., 2005). According to the ICSD, inadequate sleep hygiene is defined as a sleep disorder because of daily lifestyle activities that are inconsistent with the maintenance of good sleep quality (American Academy of Sleep Medicine, 2005).

According to the National Sleep Foundation, poor sleep quality and quantity is linked to a wide range of health problems, such as obesity, diabetes, hypertension, and depression (National sleep foundation, 2015). Sleep hygiene was found as an important predictor of sleep quality in Italian and American adolescents (Le Bourgeois, Giannotti, Cortesi, Wolfson, \& Harsh, 2005). In addition, sleep hygiene factors have a large effect on the prediction of insomnia severity (Gellis, Park, Stotsky, \& Taylor, 2014).

However, no previous studies have examined sleep hygiene practices in a large community based on a sample of the general population in Iran. Because people's sleep hygiene can have a major role in their daily function, the purpose of the current study was to determine sleep hygiene patterns and sleep hygiene behaviors and factors affecting them in the general population of Kermanshah, Iran.

\section{Material and Methods}

In the current descriptive and analytical design (cross-sectional) study, 3,091 people (1,829 (59.2\%) men and $1,262(40.8 \%)$ women) from the general population were included. The mean age of the participants was $34.7 \pm$ 14 years. According to the statistical information from the Kermanshah Health Center, the participants were randomly selected from 50 clusters of different parts of the city; 60-70 people from each cluster were selected randomly. A written consent form was completed by all the participants. The inclusion criteria were as follows: age between 12 and 65 years and living in Kermanshah. The exclusion criteria were history of psychiatric disorders and medical condition that affecting sleep.

The data collection instrument was a two-section questionnaire. The first section consisted of seven questions regarding demographics and the second section consisted of 13 items about biological rhythm and bed room environment and behaviors that affecting sleep. We named this questionnaire as Sleep Hygiene Questionnaire (SHQ). This questionnaire consisted of 13 items about biological rhythm and bed room environment and behaviors that affecting sleep. The items of SHQ were derived from the diagnostic criteria for inadequate sleep hygiene as defined in the International Classification of Sleep Disorders and other textbooks about sleep disorders.

To determine the scientific validity of the questionnaire, content validity was assessed. For this purpose, the questionnaire was distributed to 10 faculty members of psychiatry at the Medicine School of Kermanshah and was approved after evaluating the comments.

Approximately $10 \%$ of the participants retook the questionnaire after a 4-6 week (median 31 days) interval in order to measure test-retest reliability. Spearman test showed that test-retest scores were considerably correlated (0.8).

Data were collected by the students of psychiatry research at the Medical School of Kermanshah who were familiar with the study protocol. The sampling took 2 months and the data were analyzed by using SPSS version 16 software. The test results of SHQ are presented in a term quartile system, which means that frequency distributions are divided into equal fourths. One-quarter (25\%) of the cases fall below Q1 and are considered as subjects with very poor sleep hygiene (their sleep hygiene questionnaire scores were between 0 and 6 ).

The interquartile range, which is an interval from Q1 to Q3, is bounded by the range of scores that represents the middle $50 \%$ of the distribution. We divided them into two quartiles, with an interval from Q1 to Q2 (sleep hygiene questionnaire scores ranged between 7 and 9) representing subjects with poor sleep hygiene and an interval from Q2 to Q3 (sleep hygiene questionnaire scores fell between 10 and 11) representing subjects with moderate sleep hygiene.

Finally, one-quarter (25\%) of the cases were above Q3 and are considered as subjects with good sleep hygiene (sleep hygiene questionnaire scores fell between 12 and 14). 


\section{Results}

The frequency and percentages of all the research variables are shown in Table 1. Results indicate that the highest and lowest percentages were obtained for irregular woke and went up from day to day or at weekend and holidays (74.8\%) and using cigarette/tobacco before sleeping (14.3\%), respectively.

1984(64.2\%) participants were classified as having very poor sleep hygiene (score 0-6) or poor sleep hygiene (score 7-9), and 213(6.9\%) were classified as having good sleep hygiene (score 12-14) (Table 2). The mean age of very poor, poor, moderate, and good sleepers was $34.8 \pm 14.4,33.7 \pm 17.4,36.5 \pm 13.8$, and $35 \pm 13.7$ years, respectively. There was a significant difference between the age of poor and moderate sleepers. There was also a significant difference in sleep hygiene patterns with respect to sex, education level, and job (Table 3).

Table 1. Frequency and percent of all study variables

\begin{tabular}{lccc}
\hline Variable & N & $\%$ & Response rate \\
\hline 1- Take daytime naps lasting two hours & & \\
Yes & 1859 & 71 & 85 \\
No & 760 & 29 &
\end{tabular}

2- woke and went up at approximately the same time from day to day or weakened and holidays

$\begin{array}{lccc}\text { Yes } & 772 & 25.2 & 99 \\ \text { No } & 2289 & 74.8 & \end{array}$

3- Drank caffeinated beverages

$\begin{array}{lccc}\text { Yes } & 668 & 21.8 & 99.3 \\ \text { No } & 2400 & 78.2 & \\ \text { 4- Used cigarette/tobacco } & & & \\ \text { Yes } & 439 & 14.3 & 99.2 \\ \text { No } & 2627 & 85.7 & \end{array}$

5- Exercised within 4 hours of bed time (to the point of sweating)

$\begin{array}{lrrr}\text { Yes } & 582 & 19 & 99.1 \\ \text { No } & 2481 & 81 & \end{array}$

6- Worried, planned, or thought about important matters and daily activities

$\begin{array}{lccc}\text { Yes } & 1264 & 41.5 & 98.5 \\ \text { No } & 1780 & 58.5 & \\ \text { 7- Read in bed } & & & \\ \text { Yes } & 1088 & 35.6 & 98.9 \\ \text { No } & 1968 & 64.4 & \\ \text { 8-Watched TV in bed } & & & \\ \text { Yes } & 1698 & 55.3 & \\ \text { No } & 1371 & 44.7 & \\ \text { 9- Talked on the phone } & & & \\ \text { Yes } & 1021 & 33.3 & 99.2 \\ \text { No } & 2044 & 66.7 & \end{array}$

10- Slept in a room with un comfortable temperature, noisy environment and bright room
Yes
671
21.8
No $2403 \quad 78.2$
99.5

11- woke and went up at approximately the same time in weekend and holiday

$\begin{array}{llll}\text { Yes } & 1372 & 44.8 & 99.2 \\ \text { No } & 1693 & 55.2 & \end{array}$

12- Having a regular exercise program during the week

$\begin{array}{llll}\text { Yes } & 1199 & 39.3 & 98.8 \\ \text { No } & 1855 & 60.7 & 9\end{array}$




\begin{tabular}{lccc}
\hline Variable & $\mathrm{N}$ & $\%$ & Response rate \\
\hline 13- Watched clock and worried about time to sleep in bed & \\
Yes & 1230 & 40 & \\
No & 1842 & 60 & 99.4 \\
14- Ate heavy dinner & within 2 hours of going to bed) & \\
Yes & 735 & 23.9 & \\
No & 2339 & 76.1 & 99.5 \\
\hline
\end{tabular}

Table 2. Frequency and percent of sleep hygiene according to 4 categories of the study

\begin{tabular}{lll}
\hline & $\mathrm{N}$ & $\%$ \\
\hline Very poor & 529 & 17.1 \\
Poor & 1455 & 47.1 \\
Moderate & 894 & 28.9 \\
Good & 213 & 6.9 \\
Tot & 3091 & 100 \\
\hline
\end{tabular}

Table 3. Uni - variant analysis of effective factor on sleep hygiene

\begin{tabular}{|c|c|c|c|c|c|c|c|c|c|c|c|c|c|c|}
\hline \multicolumn{15}{|l|}{ Sleep hygiene } \\
\hline \multirow{2}{*}{ factors } & \multicolumn{2}{|c|}{ Very poor } & \multicolumn{3}{|l|}{ poor } & \multicolumn{3}{|c|}{ moderate } & \multicolumn{5}{|l|}{ good } & \multirow[t]{2}{*}{$P$ value } \\
\hline & $\mathrm{N}$ & $\%$ & $\mathrm{~N}$ & & $\%$ & $\mathrm{~N}$ & $\%$ & & $\mathrm{~N}$ & $\%$ & Tot & $\%$ & & \\
\hline \multicolumn{15}{|l|}{ Gender } \\
\hline Male & 326 & 17.8 & 826 & & 45.2 & 562 & 30 & & 115 & 6.3 & 1829 & 100 & & 0.007 \\
\hline Female & 199 & 15.9 & 627 & & 50 & 332 & 26 & & 96 & 7.7 & 1254 & 100 & & \\
\hline Total & 527 & 17 & 1453 & & 47.1 & 894 & 29 & & 211 & 6.8 & 3083 & 100 & & \\
\hline \multicolumn{15}{|l|}{ Education } \\
\hline $\begin{array}{l}\text { Under } \\
\text { diploma }\end{array}$ & 163 & 20.1 & 381 & & 47.1 & 218 & 26 & & 47 & 5.8 & 809 & 100 & & \\
\hline $\begin{array}{l}\text { Under } \\
\text { bachelor's } \\
\text { degree }\end{array}$ & 214 & 16.6 & 588 & & 45.5 & 401 & 31 & & 89 & 6.9 & 1292 & 100 & & 0.03 \\
\hline $\begin{array}{l}\text { Bachelor's } \\
\text { degree and } \\
\text { higher }\end{array}$ & 144 & 15 & 468 & & 48.8 & 273 & 28 & & 273 & 7.8 & 960 & 100 & & \\
\hline Total & 521 & 17 & 1437 & & 46.9 & 892 & 29 & & 211 & 6.9 & 3061 & 100 & & \\
\hline \multicolumn{15}{|l|}{ Job } \\
\hline Employee & 250 & 15.4 & 771 & & 47.4 & 476 & 29 & & 131 & 8 & 1628 & 100 & & \\
\hline Unemployed & 156 & 23.2 & 295 & & 43.9 & 177 & 26 & & 44 & 6.5 & 672 & 100 & & $<0.0001$ \\
\hline Self-employee & 110 & 15.1 & 353 & & 48.6 & 229 & 31 & & 35 & 4.8 & 727 & 100 & & \\
\hline Total & 516 & 17 & 1419 & & 46.9 & 882 & 29 & & 210 & 6.9 & 3027 & 100 & & \\
\hline \multicolumn{15}{|l|}{ Age } \\
\hline & $\mathrm{N}$ & Mean & SD & $\mathrm{N}$ & Mea & & SD & $\mathrm{N}$ & Mean & SD & $\mathrm{N}$ & Mean & SD & $P$ value \\
\hline & 526 & 34.8 & 14.4 & 1439 & 33.7 & & 17.4 & 894 & 36.5 & 13.8 & 213 & 35 & 13.7 & 0.001 \\
\hline
\end{tabular}

\section{Discussion}

The present study examined the sleep hygiene patterns and sleep hygiene behaviors of general population in Kermanshah, Iran. The greatest sleep hygiene problem was irregular sleep schedules (wake time and bedtime were different each day or wake time and bedtime were different during the weekend and holidays (74.8\%)). Previous studies demonstrated an association between irregular sleep schedule and poor sleep quality (Carney, Edinger, Meyer, Lindman, \& Istre, 2006; Kang \& Chen, 2009; Monk et al., 2006). To date, only a few studies 
have directly reported the prevalence of irregular sleep schedules in the general population, but the prevalence of irregular sleep schedules in the current study was very high, and further research is needed to examine the impact of a fixed daily sleep and wake time and sleep time regularity during the weekend and holidays.

The next major sleep hygiene problem was day-time naps lasting for $>2 \mathrm{~h}(71 \%)$. Day-time napping has been proposed to disrupt the homeostatic sleep drive (Irish, Kline, Gunn, Buysse, \& Hall, 2015), and some studies recommend avoiding naps for $>30$ min (Stepanski \& Wyatt, 2003). Regular napping is a routine behavior for many Iranian people, as also indicated in the studies by Dhand et al. and Takahashi et al. (Dhand \& Sohal, 2006; Takahashi, 2003). Whether persons who habitually indulge in day-time napping are more vulnerable to nocturnal sleep problems remains to be known. Individual and cultural differences may influence the consequences of day-time napping on nocturnal sleep. More importantly, in this population, prolonged habitual napping ( $>2 \mathrm{~h}$ ) may be associated with higher morbidity and mortality. However, further investigation would be required to determine if avoidance of prolonged naps may improve sleep in the general population.

Regular exercise is an important and commonly recommended for sleep hygiene, but exercise should be avoided close to bed time (Stepanski \& Wyatt, 2003). Based on the current findings, $60.7 \%$ of the general population did not have a regular exercise program during the week. Few studies have assessed the effect of exercise training on sleep in healthy populations. Awad et al. reported that exercise reduced the incidence of sleep-disordered breathing (Awad, Malhotra, Barnet, Quan, \& Peppard, 2012).

Other major sleep hygiene problems were watching television in bed (55.3\%), reading in bed (35.6\%), talking on the phone $(33.3 \%)$, and drinking caffeinated beverages $(21.8 \%)$. In conclusion, only $6.9 \%$ of all participants had good sleep hygiene, whereas $64.2 \%$ of participants had poor or very poor sleep hygiene. One reason may be the median age of participants (35 year) and some related factors (e.g. kids, an ill person in the family that needs care). Malakoti et al. showed that $82.6 \%$ of men and women, aged 60 years or older suffered from poor sleep quality (Malakouti, Foroughan, Nojomi, Ghalebandi, \& Zandi, 2009) compared with 56\% of Americans, $31 \%$ of western Europeans, and 29\% of Japanese (Leger, Poursian, Neubouer, \& Vchiyama, 2008). The higher prevalence of sleep disorders in Malakoti et al. study may be due to the number of elderly participants, but another reason based on our study may be poor sleep hygiene in Iran.

In the present study, sleep hygiene showed significant difference with respect to sex. Poor sleep hygiene was seen in men more than women. Evidence shows that the consumption of alcohol, cigarettes, and caffeine causes sleep hygiene disorder (Irish et al., 2015; Storfer-Isser, lebourgeois, Harsh, Tomposett, \& Redline, 2013). The fact that in Iran consumption of such products is more prevalent among men than in women may be the reason for the significant difference with respect to sex.

There was a significant difference in sleep hygiene with respect to job. The current findings showed that unemployed people had poor sleep hygiene, which may be because of the work rules of on-time presence for employees.

The results also revealed that age factored a significant difference in sleep hygiene. As previously mentioned younger people had poor sleep hygiene, which may be because of the fact that they are not trained sufficiently or most of the younger people do not have a job and obligation for wake up in the morning. Nowadays the role of media and mobile phone and virtual social networks in younger peoples is important.

There was also a significant difference in sleep hygiene with respect to the level of education. The higher education levels are associated with higher sleep hygiene. For instance, Cho et al. found that the use of TV in bed room can be decreased by increasing education level, which can in turn have an impact on sleep hygiene (Cho, Kim, \& Lee, 2013).

As conclusion we can say that poor sleep hygiene were more frequent in Iranian population and the major problem in sleep hygiene in our study was inappropriate sleep schedule including instability bed and wake time and daily napping more than 2 hours.

\section{Strengths, Limitations, and Considerations}

To the best of our knowledge, this is the first study to assess sleep hygiene using a large sample size in Iran and investigate a large number of factors that may be associated with adult sleep hygiene. The study was, however, restricted to only Kermanshah in Iran.

\section{Conflict of Interest}

The authors declare that there is no conflict of interests regarding the publication of this paper. 


\section{References}

American Academy of Sleep Medicine. (2005). International classification of sleep disorders: Diagnostic and coding manual (2nd ed.). Westchester, IL: Author.

Awad, K. M., Malhotra, A., Barnet, J. H., Quan, S. F., \& Peppard, P. E. (2012). Exercise is associated with a reduced incidence of sleep-disordered breathing. Am J Med, 125(5), 485-490. http://dx.doi.org/10.1016/j. amjmed.2011.11.025

Baldwin, C. M., Griffith, K. A., Nieto, F. J., O'Connor, G. T., Walsleben, J. A., \& Redline, S. (2001). The association of sleep disordered breathing and sleep symptoms with quality of life in the Sleep Heart Health Study. Sleep, 24, 96-105.

Brown, F. C., Buboltz, W. C., \& Soper, B. (2002). Relationship of sleep hygiene awareness sleeps hygiene practices, and sleep quality in university students. Behav Med, 28, 33-38. http://dx.doi.org/10.1080/08964 280209596396

Carney, C. E., Edinger, J. D., Meyer, B., Lindman, L., \& Istre, T. (2006). Daily activities and sleep quality in college students' chronobiol. Int, 23, 623-637.

Cho, S., Kim, G. S., \& Lee, J. H. (2013). Psychometric evaluation of the sleep hygiene index: A sample of patients with chronic pain. Health Quality Life Outcomes, 11, 123. http://dx.doi.org/10.1186/1477-7525 $-11-213$

Dhand, R., \& Sohal, H. (2006). Good sleep, bad sleep! The role of daytime naps in healthy adults. Cure Opin Pulm Med, 12(6), 379-382.

Gellis, L. A., Park, A., Stotsky, M. T., \& Taylor, D. J. (2014). Associations between sleep hygiene and insomnia severity in college students: Cross-sectional and prospective analyses. Behav Ther, 45(6), 806-816. http://dx.doi.org/10.1016/j.beth.2014.05.002

Gottlieb, D. J., Redline, S., Nieto, F. J., Baldwin, C. M., Newman, A. B., Resnick, H. E., \& Punjabi, N. M. (2006). Association of usual sleep duration with hypertension: The Sleep Heart Health Study. Sleep, 29(8), 1009-1014.

Gottlieb, D. J., Yenokyan, G., Newman, A. B., O'Connor, G. T., Punjabi, N. M., Quan, S. F., ... Shahar, E. (2010). Prospective study of obstructive sleep apnea and incident coronary heart disease and heart failure: The sleep heart health study. Circulation, 122(4), 352-360. http://dx.doi.org/10.1161/CIRCULATIONAHA. 109.901801

Irish, L. A., Kline, C. E., Gunn, H. E., Buysse, D. J., \& Hall, M. H. (2015). The role of sleep hygiene in promoting public health: A review of empirical evidence. Sleep Med Rev, 22, 23-36. http://dx.doi.org/10. 1016/j.smrv.2014.10.001

Jefferson, C. D., Drake, C. L., Scofield, H. M., Myers, E., McClure, T., Roehrs, T., \& Roth, T. (2005). Sleep hygiene practices in a population-based sample of insomniacs. Sleep, 28(5), 611-615.

Kang, J. H., \& Chen, S. C. (2009). Effects of an irregular bedtime schedule on sleep quality, daytime sleepiness, and fatigue among university students in Taiwan. BMC Public Health, 9, 248. http://dx.doi.org/10.1186/ $1471-2458-9-248$

Kapur, V. K., Redline, S., Nieto, F. J., Young, T. B., Newman, A. B., Henderson, J. A., \& Sleep Heart Health Research Group. (2002). The relationship between chronically disrupted sleep and healthcare use. Sleep, 25, 289-296.

Le Bourgeois, M. K., Giannotti, F., Cortesi, F., Wolfson, A. R., \& Harsh, J. (2005). The relationship between reported sleep quality and sleep hygiene in Italian and American adolescents. Pediatrics, 115, 257-265. http://dx.doi.org/10.1542/peds.2004-0815H

Leger, D., Poursian, B., Neubouer, D., \& Vchiyama, M. (2008). An international survey of sleeping problems in the general population. Curr Med Res opin, 24(1), 307-317. http://dx.doi.org/10.1185/030079907X253771

Malakouti, S. K., Foroughan, M., Nojomi, M., Ghalebandi, M. F., \& Zandi, T. (2009). Sleep patterns, sleep disturbances and sleepiness in retired Iranian elders. International Journal of Geriatric psychiatry, 24(11), 1201-1208. http://dx.doi.org/10.1002/gps.2246

Masa, J. F., Rubio, M., \& Findley, L. J. (2000). Habitually sleepy drivers have a high frequency of automobile crashes associated with respiratory disorders during sleep. Am J Respir Crit Care Med, 162, 1407-1412. 
http://dx.doi.org/10.1164/ajrccm.162.4.9907019

Meier-Ewert, H. K., Ridker, P. M., Rifai, N., Regan, M. M., Price, N. J., Dinges, D. F., \& Mullington, J. M. (2004). Effect of sleep loss on C-reactive protein, an inflammatory marker of cardiovascular risk. J Am Coll Cardiol, 43(4), 678-683. http://dx.doi.org/10.1016/j.jacc.2003.07.050

Monk, T. H., Buysse, D. J., Billy, B. D., Fletcher, M. E., Kennedy, K. S., Schlarb, J. E., \& Beach, S. R. (2006). Circadian type and bed timing regularity in 654 retired seniors: Correlations with subjective sleep measures. Sleep, 34(2), 235-239.

National sleep foundation, Myth and facts about sleep. (2015). Retrieved from http://www.sleepfoundation. org/how-sleep-facts-about-sleep/page/0/2

Ozdemir, P. G., Boysan, M., Selvi, Y., Yildirim, A., \& Yilmaz, E. (2015). Psychometric properties of the Turkish version of the Sleep Hygiene Index in clinical and non-clinical samples. Compr Psychiatry, 59, 135-140. http://dx.doi.org/10.1016/j.comppsych.2015.02.001

Stepanski, E. J., \& Wyatt, J. K. (2003). Use of sleep hygiene in the treatment of insomnia. Sleep Medicine Reviews, 7(3), 215-225. http://dx.doi.org/10.1053/smrv.2001.0246

Storfer-Isser, A., lebourgeois, M., Harsh, J., Tomposett, C. J., \& Redline, S. (2013). Psychometric properties of the adolescent sleep hygiene scale. J sleep Res, 22, 707-716. http://dx.doi.org/10.1111/jsr.12059

Takahashi, M. (2003). The role of prescribed napping in sleep medicine. Sleep Medicine Reviews, 7, 227-235. http://dx.doi.org/10.1053/smrv.2002.0241

Walia, H. K., Li, H., Rueschman, M., Bhatt, D. L., Patel, S. R., Quan, S. F., ... Mehra, R. (2014). Association of severe obstructive sleep apnea and elevated blood pressure despite antihypertensive medication use. $J$ Clin Sleep Med, 10(8), 845-846. http://dx.doi.org/10.5664/jcsm.3946

\section{Copyrights}

Copyright for this article is retained by the author(s), with first publication rights granted to the journal.

This is an open-access article distributed under the terms and conditions of the Creative Commons Attribution license (http://creativecommons.org/licenses/by/3.0/). 